\title{
Characterization and Distribution of Mating Type Genes in the Dothistroma Needle Blight Pathogens
}

\author{
Marizeth Groenewald, Irene Barnes, Rosie E. Bradshaw, Anna V. Brown, Angie Dale, Johannes Z. Groenewald, \\ Kathy J. Lewis, Brenda D. Wingfield, Michael J. Wingfield, and Pedro W. Crous
}

First, sixth, and tenth authors: CBS Fungal Biodiversity Centre, Uppsalalaan 8, 3584 CT Utrecht, Netherlands; second, eighth, and ninth authors: Forestry and Agricultural Biotechnology Institute (FABI), Department of Genetics, University of Pretoria, Pretoria 0002, South Africa; third author: Institute of Molecular BioSciences, Massey University, Palmerston North, New Zealand; fourth author: Forest Research, Alice Holt Lodge, Wrecclesham, Farnham, Surrey, GU10 4LH, United Kingdom; and fifth and seventh authors: University of Northern British Columbia, 3333 University Way, Prince George, BC V2N 4Z9, Canada.

Accepted for publication 25 January 2007.

\begin{abstract}
Groenewald, M., Barnes, I., Bradshaw, R. E., Brown A. V., Dale, A., Groenewald, J. Z., Lewis, K. J., Wingfield, B. D., Wingfield, M. J., and Crous, P. W. 2007. Characterization and distribution of mating type genes in the Dothistroma needle blight pathogens. Phytopathology 97:825-834.

Dothistroma septosporum and D. pini are the two causal agents of Dothistroma needle blight of Pinus spp. in natural forests and plantations. Degenerate primers amplified portions of mating type genes (MAT1-1-1 and MAT1-2) and chromosome walking was applied to obtain the fulllength genes in both species. The mating-type-specific primers designed

land collections, where only the asexual form of the fungus has been found. In contrast, both mating types of D. septosporum were present in collections from Canada and Europe, where the sexual state is known. Intriguingly, collections from South Africa and the United Kingdom, where the sexual state of the fungus is unknown, included both mating types. In $D$. pini, for which no teleomorph is known, both mating types were present in collections from the United States. These results provided new insights into the biology and global distribution of two of the world's most important pine pathogens and should facilitate management of the diseases caused by these fungi.
\end{abstract} in this study could distinguish between the morphologically similar $D$. pini and $D$. septosporum and between the different mating types of these species. Screening of isolates from global collections of $D$. septosporum showed that only MAT2 isolates are present in Australian and New Zea-
Additional keywords: ascomycetes, heterothallic, Mycosphaerella, sexual reproduction.
Dothistroma needle blight, also known as red band needle blight, is one of the most important diseases of Pinus spp., both in natural forest ecosystems and particularly in plantations of nonnative pines $(9,19,20,27)$. The disease owes its international notoriety to the fact that it has been one of the most important constraints to the development of plantation forestry in many countries of Africa as well as in New Zealand, Australia, Chile, and other South American countries $(19,20,27)$. The disease is particularly severe on Pinus radiata D. Don. This species is highly desirable for its rapid growth and exceptional timber and, consequently, it was one of the first nonnative tree species established in intensively managed plantations in the tropics and Southern Hemisphere. Outbreaks of Dothistroma needle blight on $P$. radiata led to devastating losses and resulted in the abandonment of $P$. radiata from plantation forestry in many countries $(11,31,51)$.

The main causal agent of Dothistroma needle blight has been a matter of considerable taxonomic confusion. Thus, in different parts of the world, the disease has been attributed to either a single pathogen, different species of a pathogen, or varieties of a species. This also has differed depending on whether the pathogen was considered introduced or native in areas where the disease has been studied. In a recent study based on DNA sequence comparisons, two distinct phylogenetic lineages for Dothistroma isolates were identified (2). These clearly separated Dothistroma

Corresponding author: M. Groenewald;

E-mail address: m.groenewald@ cbs.knaw.nl

doi:10.1094/PHYTO-97-7-0825

(C) 2007 The American Phytopathological Society septosporum, which has a worldwide distribution, and D. pini, until recently found only in the north-central United States. This study also showed that the disease which devastated plantations of $P$. radiata in the Southern Hemisphere is caused by $D$. septosporum. Recently, D. pini has been found infecting $P$. palassiana D. Don. in the Ukraine (I. Barnes, unpublished data) and it clearly has a distribution much wider than was believed at the time of the study of Barnes et al. (2).

Dothistroma needle blight, now known to have been caused by $D$. septosporum, resulted in huge damage to $P$. radiata plantations in the Southern Hemisphere in the 1950s and 1960s $(9,19,20,27)$. Consequently, considerable research was conducted on the disease and great efforts were made to minimize its impact $(8,19$, 20,41,46). These included selection of alternative species, tree breeding, agricultural practices, and the first examples of aerial applications of chemical fungicides in forest plantations (19). Although the disease has continued to be important, it generally is considered to be under reasonable control. There has, however, been a recent resurgence of the disease in various Northern Hemisphere countries and this has raised concern that a new wave of losses might occur elsewhere in the world $(5,53)$.

Almost nothing is known regarding the genetic diversity among isolates of $D$. septosporum and $D$. pini. D. septosporum first was identified in New Zealand in 1964 (21). A study by Hirst et al. (26) applied random amplified polymorphic DNA (RAPD) markers to a population of $D$. septosporum (previously described as $D$. pini) from New Zealand and the results showed no genetic variation. These results support the hypothesis that it is an introduced pathogen that has been spreading asexually ever since its introduction into that country. 
The sexual state of D. septosporum is a species of Mycosphaerella known as Mycosphaerella pini Rostr. (17). In most countries of the Southern Hemisphere where D. septosporum has long been an important forest pathogen, only the anamorph has been reported (2,5,14; M. J. Wingfield, unpublished data). In contrast, no sexual state has ever been reported for $D$. pini. The absence or rarity of a sexual state for either of these fungi could be the result of selection pressure and a reduced need for sexual reproduction (14). Likewise, lower frequency and limited distribution of the teleomorph compared with the anamorph suggests that the primary method of dispersal of the fungus could be an asexual cycle. Here, conidia rather than ascospores would represent the inoculum of primary epidemiological importance $(10,28)$.

Mating type genes play an important part in the biology and evolution of fungal species. Thus, knowledge of these genes can provide insight into the potential prevalence of sexual reproduction in different species. Some heterothallic Pyrenomycetes and Discomycetes can contain up to four genes at the mating type 1 idiomorph (MAT1-1) of the MAT locus $(40,43,44,55)$. These include the MAT1-1-1 encoding an $\alpha$ domain protein, the MAT11-2 encoding an amphipathic $\alpha$ helix protein, the MAT1-1-3 gene encoding a high mobility group (HMG) domain protein, and the MAT1-1-4 gene encoding a metallothionein protein. Only one gene has been characterized for the mating type 2 idiomorph (MAT1-2) and it encodes a regulatory protein with an HMG domain. The DNA sequences of the idiomorphs, located at the MAT locus of individuals of two different mating types, are unrelated and, therefore, cannot be called alleles; however, these sequences are flanked by conserved regions (32). The formal nomenclature that is proposed for mating type genes of heterothallic ascomycetes is used here for the MAT1-1-1 and, because only a single MAT1-2 gene has been identified for filamentous ascomycetes, this gene is referred to as MAT1-2 (49).

DNA and amino acid sequences of the MAT1-1-1 and MAT1-2 genes in fungi show no obvious similarities, although the mating type locus has common flanking regions (48). Except for the HMG and $\alpha$ domains, the similarity of homologous mating type genes usually is very low between different species (47). The direct target genes of the mating type proteins have not yet been described, although there is evidence for the control of some genes, such as pheromone genes (4). Mating type genes have been described from various sexual and presumably asexual fungi that are close relatives of the genus Dothistroma (Mycosphaerellaceae). Detailed analyses have been done on the distribution of the mating types of the sexually reproducing $M$. graminicola $(50,56)$ and the presumably asexual species Septoria passerinii (23), Cercospora beticola, C. zeae-maydis, and C. zeina (25). Equal distribution of the mating types was found in most of the populations from these five species sampled from different geographical scales, indicating that sexual stages probably exist for the latter four apparently asexual species.

D. septosporum first was described from Idaho (United States) but now is seen in many parts of the world (2). In most of the areas where this species has been introduced and causes serious disease, only the asexual state of the fungus is ever seen. This raises the interesting question as to whether this could be attributed to the introduction of only one mating type into these new environments. Thus, the aims of this study were to characterize the mating type gene or genes of the causal agents of Dothistroma needle blight and to ascertain which mating types are present in the different countries where diseases caused by these fungi occur. To achieve this objective, the full-length MAT1-1-1 and MAT1-2 genes of $D$. septosporum and $D$. pini were isolated and sequenced using polymerase chain reaction (PCR)-based techniques. This made it possible to develop a multiplex PCR method for the rapid screening of MAT1-1-1 and MAT1-2 in isolates of the pathogens. A global collection of isolates subsequently was screened to determine which mating types are present in these collections.

\section{MATERIALS AND METHODS}

Fungal isolates. In all, 230 Dothistroma isolates obtained from various locations in 15 countries were chosen to represent a global distribution of Dothistroma spp. (Table 1). Countries for which more than one isolate was screened included Austria $(n=$ $10)$, Canada $(n=106)$, Chile $(n=10)$, New Zealand $(n=38)$, Poland $(n=11)$, South Africa $(n=11)$, Ukraine $(n=4)$, the United Kingdom $(n=10)$, and the United States $(n=17)$. Isolates were obtained from different culture collections and standard protocols were used to isolate the genomic DNA.

The initial screening of the mating type genes was undertaken for D. septosporum using two isolates. These included CBS 116489 obtained from $P$. radiata in Tzaneen, South Africa and American Type Culture Collection (ATCC) MYA-605 obtained from $P$. radiata in Rotorua, New Zealand. For $D$. pini, four isolates were used: CBS 116485, obtained from P. nigra in Crystal Township, MI; CBS 116487, obtained from P. nigra in Evergreen Township, MI; CBS 116483, obtained from River Township, MI; and CBS 117609, obtained from $P$. palassiana in Tsyurupinsk, Ukraine. The identities of the six isolates used for the screening of the mating types previously had been confirmed using comparisons of DNA sequence data for the internal transcribed spacer (ITS) regions of the ribosomal DNA (2; J. Z. Groenewald, unpublished data).

Isolation and characterization of MAT1-1-1 of Dothistroma spp. The MAT1-1-1-specific degenerate primers (MgMfSpMat11f1 and MgMfSpMat1-1r2) (Table 2), designed by Groenewald et al. (25), were used to screen and amplify a partial region of the MAT1-1-1 genes of the Dothistroma isolates.

The PCR mixtures and amplification reactions were the same as described by Groenewald et al. (25) for the amplification of the partial MAT1-1-1 in Cercospora spp. The PCR products obtained were separated by electrophoresis at $80 \mathrm{~V}$ for $1 \mathrm{~h}$ on a $1 \%$ (wt/vol) agarose gel containing ethidium bromide at $0.1 \mu \mathrm{g} / \mathrm{ml}$ in $1 \times$ Tris-acetate-EDTA buffer (0.4 M Tris, $0.05 \mathrm{M}$ sodium acetate, and 0.01 M EDTA, pH 7.85) and visualized under UV light. Amplicons were sequenced in both directions using the PCR primers and a DYEnamic ET Terminator Cycle Sequencing kit (Amersham Biosciences, Roosendaal, Netherlands) following the manufacturer's recommendations. The products were analyzed on an ABI Prism 3730 DNA Sequencer (Applied Biosystems, Foster City, CA). A consensus sequence was computed from the forward and reverse sequences with SeqMan from the Lasergene package (DNA-STAR, Madison, WI).

Internal primers were designed in the partially sequenced MAT1-1-1 genes for each of the species (CBS 116489 for $D$. septosporum and CBS 116487 for $D$. pini). In order to obtain the full-length genes, these internal primers were used together with the appropriate primers from the DNA walking speedup kit (Seegene Inc., Rockville, MD) to determine additional sequences upstream and downstream of the partial MAT1-1-1 sequences. The Blastx algorithm (1) was used to compare the sequences obtained from the two Dothistroma spp. with protein sequences of other fungi present in the National Center for Biotechnology Information (NCBI) nonredundant protein database. The geneid web server (v1.2; Research Unit on Biomedical Informatics of IMIM, Barcelona, Spain) was used to predict the gene and intron or exon boundaries using the genetic code of Neurospora crassa. The conversion of DNA sequences to putative amino acid sequences was done using the translation tool of the proteomics server ExPASy (18). The percentage of identities between the predicted MAT1-1-1 gene sequences for the Dothistroma spp. was calculated using the alignment tool of ALIGN (37).

Isolation and characterization of MAT1-2 of Dothistroma spp. The MAT1-2-specific degenerate primers (MgMfSpMat1-2f2 and MgMfSpMat1-2fr1) (Table 2), designed by Groenewald et al. (25), were used to screen isolates of D. septosporum and D. pini 
TABLE 1. Origins of the Dothistroma septosporum and D. pini strains used during this study and the distribution of their mating types

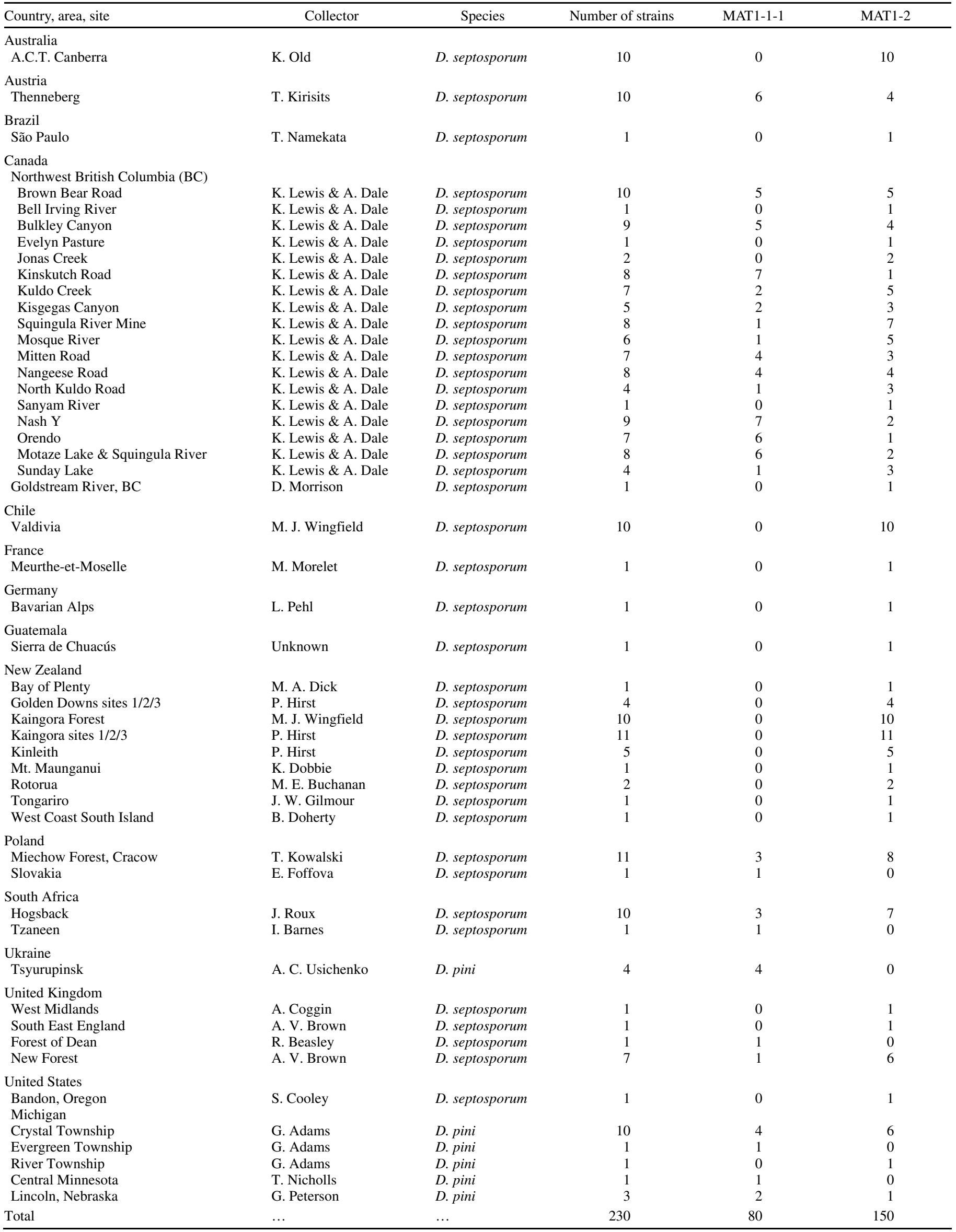


to obtain a partial region of the MAT1-2 genes. The same PCR conditions described above were used to amplify the partial MAT1-2 regions. Twelve internal primers were designed in the partially sequenced MAT1-2 sequences for both species (ATCC MYA-605 for D. septosporum and CBS 116485 for D. pini) and the chromosome walking method also was used to obtain the fulllength MAT1-2 genes. The same procedure and programs described for the characterization and analyses of the MAT1-1-1 sequences were used to characterize and analyze the Dothistroma MAT1-2 sequences.

Development and screening of $D$. pini and $D$. septosporum mating-type-specific primers. Dothistroma MAT1-1-1-specific primers (Table 2) were designed from the aligned MAT1-1-1 sequences of $D$. pini and D. septosporum (GenBank accession nos. DQ915449 and DQ915450, respectively). The forward primers were designed to be specific for D. septosporum (DseptoMat1f) or D. pini (DpiniMat1f2) and, therefore, are both species and mating type specific. The reverse primer (DotMat1r) was designed from homologous regions within the MAT1-1-1 genes and, therefore, is only mating type specific.

Dothistroma MAT1-2-specific primers (Table 2) were designed from the aligned MATl-2 sequences of D. pini and D. septosporum (GenBank accession nos. DQ915451 and DQ915452, respectively). The two forward primers were designed in regions of the genes that were variable between the two species. DseptoMat2f was designed to be specific for D. septosporum and DpiniMat2f for $D$. pini, and both, therefore, are species and mating type specific. The reverse primer (DotMat2r) was designed from homologous regions within both the MATl-2 genes and, thus, is only mating type specific.

Multiplex PCR was used to screen for the MAT1-1-1 or the MAT1-2 of D. pini and D. septosporum in two separate reactions. The reaction mixtures had a total volume of $12.5 \mu \mathrm{l}$ and contained $0.7 \mu$ l of diluted genomic DNA, 1× PCR buffer (Bioline, Randolph, MA), $48 \mu \mathrm{M}$ each of the dNTPs, 4 pmol of each primer, $1 \mathrm{mM} \mathrm{MgCl}_{2}$, and 0.7 units of Taq polymerase (Bioline, Randolph, MA). The amplification reactions were done on a GeneAmp PCR System 9600 (Applied Biosystems). The initial denaturation step was done at $94^{\circ} \mathrm{C}$ for $5 \mathrm{~min}$, followed by 40 cycles of $94^{\circ} \mathrm{C}(20 \mathrm{~s}), 65^{\circ} \mathrm{C}(20 \mathrm{~s})$, and $72^{\circ} \mathrm{C}(40 \mathrm{~s})$. A final elongation step at $72^{\circ} \mathrm{C}(5 \mathrm{~min})$ was included in the run. The resulting PCR products were visualized as described above.

Phylogenetic analyses. The nucleotide sequences of the $\alpha$ domain (MAT1-1-1) and HMG domain (MAT1-2) of D. septosporum and $D$. pini determined in this study and additional mating type sequences for other species representing different fungal orders downloaded from NCBI's GenBank database were used for phylogenetic analyses. These sequences were analyzed using the mating type gene sequences of Magnaporthe grisea (GenBank accession nos. AB080672 and AB080673, respectively) as the outgroup. All phylogenetic analyses were done using Phylogenetic Analysis Using Parsimony (PAUP) v4.0b 10 (Swofford, D. L. 2003. Sinauer Associates, Sunderland, MA). Maximum parsimony analyses were conducted as described by Groenewald et al.
(24). All sequences generated were deposited in GenBank, and the alignments and trees were deposited in TreeBASE (TreeBASE accession no. SN3047).

\section{RESULTS}

Isolation and characterization of MAT1-1-1 in Dothistroma spp. The degenerate primers MgMfSpMAT1-1f1 and MgMfSpMAT1-1r2 amplified a fragment of $914 \mathrm{bp}$ for three of the six Dothistroma isolates tested (Fig. 1). The fragments obtained from strains CBS 116489, CBS 117609, and CBS 116487 were sequenced. The translated sequence of the fragment obtained from strain CBS 116489 (D. septosporum) showed 39 and $46 \%$ identity to a 229 - and 63-amino-acid (aa) region of the M. graminicola MAT1 protein and $32 \%$ identity to a 213 -aa region of the $S$. passerinii MAT1 protein using Blastx on the GenBank database. This confirmed that the 914-bp fragment is part of the MAT1-1-1 gene of D. septosporum.

Sequences for the fragments obtained from the $D$. pini strains (CBS 117609 and CBS 116487) showed $100 \%$ identity to each other in this region. The translated sequences showed $39 \%$ identity to a 226 -aa $\left(\mathrm{E}=2 \times 10^{-30}\right)$ and $37 \%$ identity to a 78 -aa region $\left(\mathrm{E}=2 \times 10^{-30}\right)$ of the $M$. graminicola mating type $1-1$ protein (GenBank accession no. AAL30838). It also showed 32\% identity to a 218 -aa region $\left(\mathrm{E}=5 \times 10^{-18}\right)$ of the $S$. passerinii MAT-1 protein (GenBank accession no. AAO49357). This confirmed that the 914-bp fragment is part of the MAT1-1-1 gene of D. pini.

Four chromosome walking steps were used to obtain the fulllength MAT1-1-1 gene sequences for D septosporum and D. pini. The geneid software predicted that the MAT1-1-1 genes of both species contained four exons. The predicted length of the genes and the exon and intron positions are illustrated in Figure 2. Although the number of nucleotide and amino acid residues was the same for the MATI-1-1 of D. septosporum and D. pini, an identity of 94.1 and $94.3 \%$ was found between the 1,311-nucleotide and the 387-aa residues, respectively. All introns of the MAT1-1-1 from both species contained a perfect lariat sequence (RCTRAC), except for the second intron of the MAT1-1-1 of D. septosporum. When this intron is included in the coding region, an early stop codon is introduced in the reading frame, indicating that this is a true intron. The positions of the three predicted introns in the Dothistroma spp. studied correlate with those found for Cercospora spp. (25). The number of predicted introns (two) in the conserved $\alpha$ domain of the Dothistroma spp. correlated with the number predicted for the same region in M. graminicola (50) and S. passerinii (23).

Isolation and characterization of MAT1-2 of Dothistroma spp. The degenerate primers MgMfSpMAT1-2f2 and MgMfSpMAT1-2r1 amplified a fragment of $332 \mathrm{bp}$ for the Dothistroma isolates that did not amplify the 914-bp fragment using the MAT1-1-1 degenerate primers (Fig. 1). An extra 180-bp fragment also was obtained from the two D. septosporum strains and an extra 280-bp fragment from the four $D$. pini strains. The 332-bp fragment obtained from strain ATCC MYA-605 (D. septo-

TABLE 2. Primers used during this studya

\begin{tabular}{|c|c|c|}
\hline Primer & $5^{\prime}-3^{\prime}$ & Description \\
\hline MgMfSpMat1-1f1 & CATTNGCNCATCCCTTTG & MAT1-1-1-specific degenerate primer \\
\hline MgMfSpMat1-1r2 & GGCTTNGANACCATGGTGAG & MAT1-1-1-specific degenerate primer \\
\hline MgMfSpMat1-2f2 & CAAAGAANGCNTTCNTGATCT & $M A T 1$-2-specific degenerate primer \\
\hline MgMfSpMat1-2r1 & TTCTTCTCNGATGGCTTGC & $M A T 1-2$-specific degenerate primer \\
\hline DseptoMat1f & 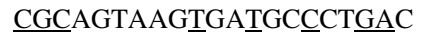 & Dothistroma septosporum MAT1-1-1-specific primer \\
\hline DpiniMat1f2 & 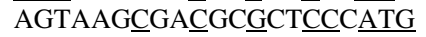 & D. pini MAT1-1-1MAT1-specific primer \\
\hline DotMat1r & TTGCCTGACCGGCTGCTGGTG & Dothistroma MAT1-1-1-specific primer \\
\hline DseptoMat2f & GTGAGTGA $\underline{A}$ CGCCGCACATGG & D. septosporum MAT1-2-specific primer \\
\hline DpiniMat2f & 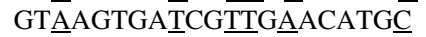 & D. pini MAT1-2-specific primer \\
\hline DotMat2r & 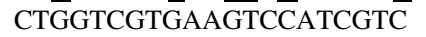 & Dothistroma MAT1-2-specific primer \\
\hline
\end{tabular}

${ }^{a}$ Nucleotides specific to the given Dothistroma sp. are underlined. 


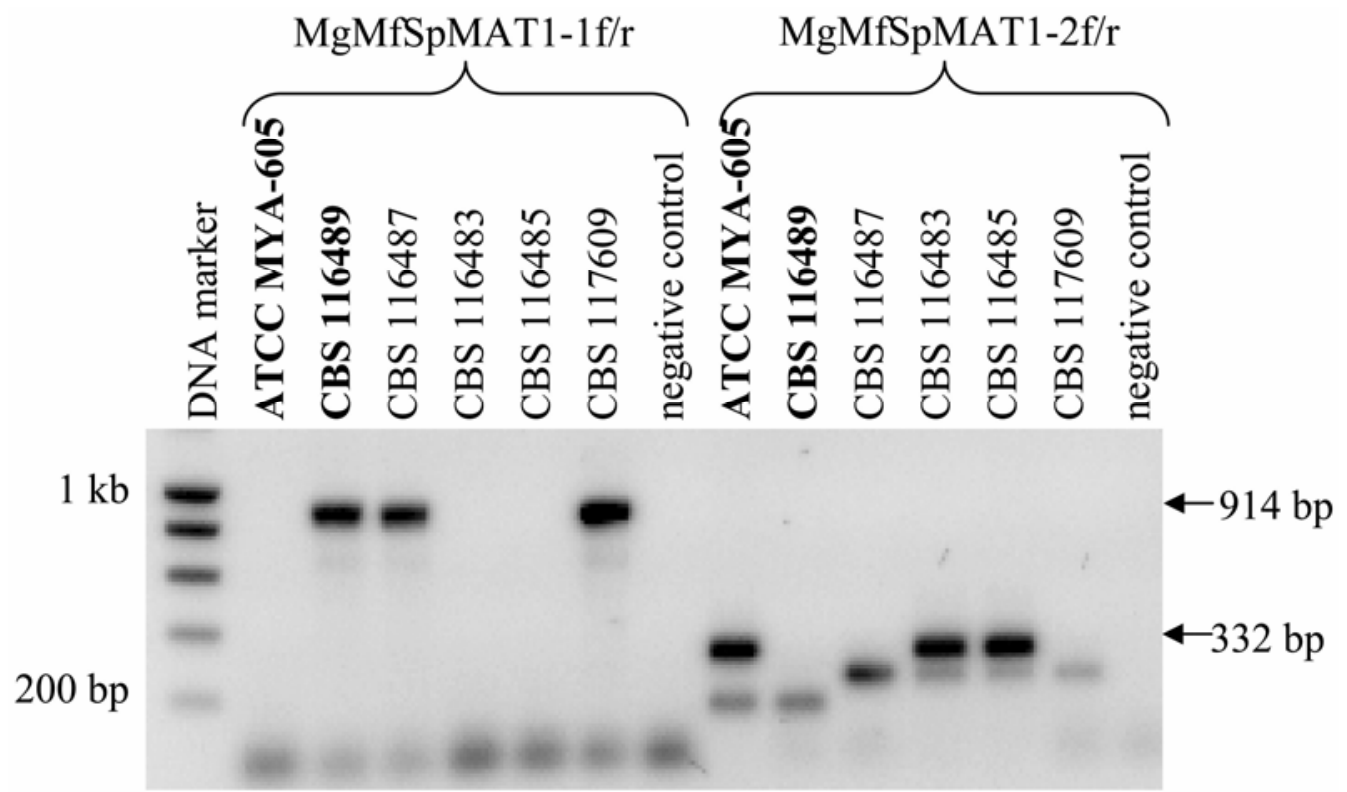

Fig. 1. Amplification products obtained from Dothistroma septosporum (in bold face) and D. pini isolates containing the partial MAT1-1-1 (914-bp) and MAT1-2 (332-bp) genes using the degenerate primer pairs MgMfSpMAT1-1 and MgMfSpMAT1-2, respectively.
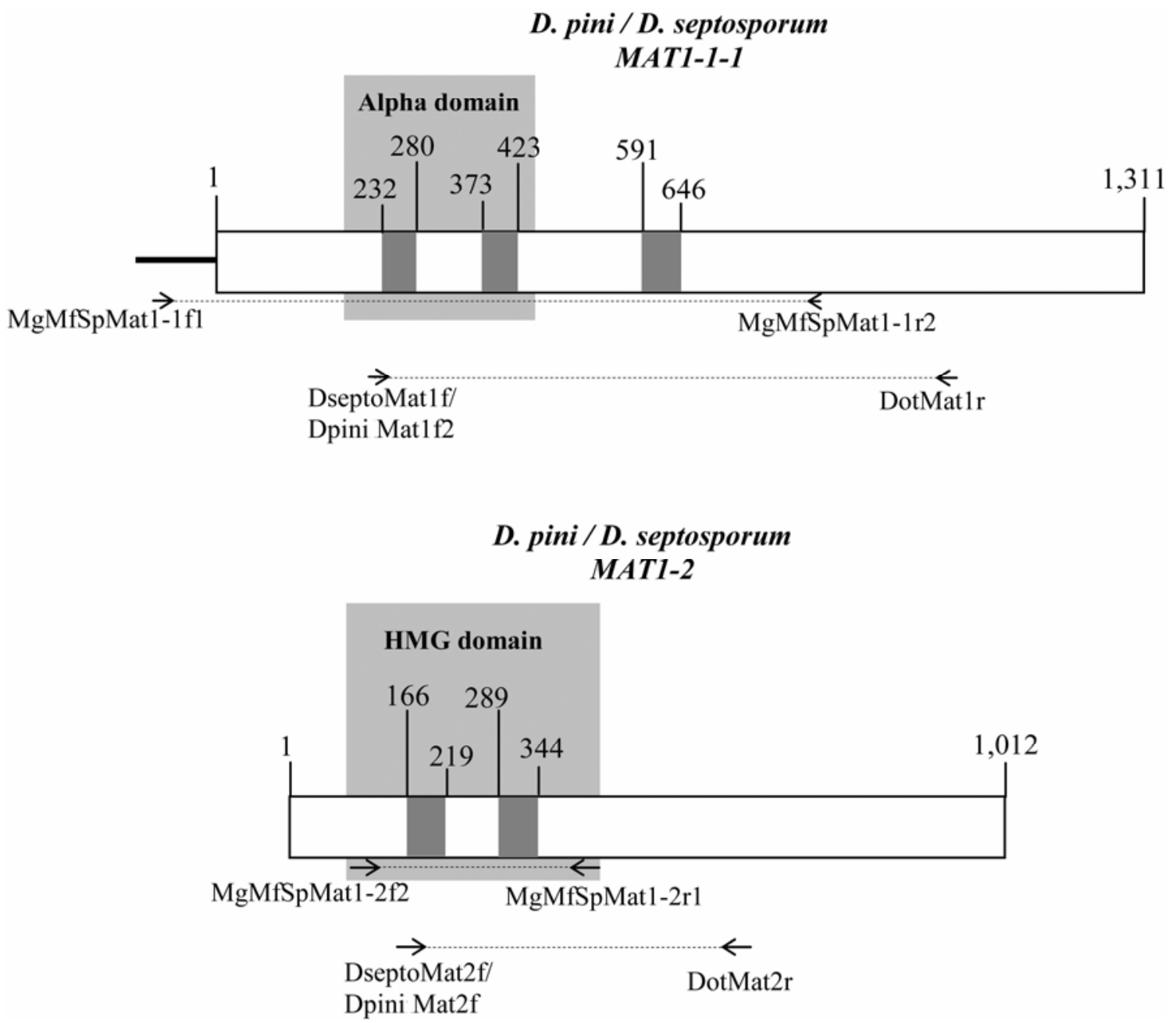

Fig. 2. Diagrammatic representation of the full-length MAT1-1-1 and MAT1-2 genes of Dothistroma septosporum and D. pini. The predicted sites of exons (white bars), and introns (black bars) are shown, and their locations (nucleotide position) are indicated. The areas amplified by the MgMfSpMAT1-1 and MgMfSpMAT12 primer sets as well as the mating-type-specific primers for each species are indicated. 
sporum) was sequenced, and the translated sequence showed $55 \%$ identity to a 65 -aa $\left(\mathrm{E}=1 \times 10^{-19}\right)$ and $70 \%$ identity to a 27 -aa region $\left(\mathrm{E}=1 \times 10^{-19}\right)$ of the $M$. graminicola mating type 1-2 protein (GenBank accession no. AAL30836) as well as 50\% identity to a 65 -aa region $\left(\mathrm{E}=7 \times 10^{-17}\right)$ of the $S$. passerinii MAT2 protein (GenBank accession no. AAO49358) using Blastx on the GenBank database. This confirmed that the 332-bp fragment is part of the MAT1-2 gene of D. septosporum. The 332-bp translated sequences for the fragments obtained from the two $D$. pini strains (CBS 116483 and CBS 116485) showed 52\% identity to a 65 -aa $\left(\mathrm{E}=1 \times 10^{-19}\right)$ and $68 \%$ identity to a 29 -aa region $(\mathrm{E}=1 \times$ $10^{-19}$ ) of the M. graminicola mating type 1-2 protein (GenBank accession no. AAL30836) as well as a $47 \%\left(\mathrm{E}=7 \times 10^{-17}\right)$ and $68 \%$ identity $\left(\mathrm{E}=7 \times 10^{-17}\right)$ to the same amino acid regions of the S. passerinii MAT-2 protein (GenBank accession no. AAO49358). This confirmed that the 332-bp fragment is part of the MAT1-2 gene of D. pini. Sequences for the 180-bp (D. septosporum) and 280-bp (D. pini) fragments showed no homology to protein sequences available in GenBank.

For both of the species, four chromosome walking steps were used to obtain the full-length MAT1-2 gene sequences. The geneid software predicted that the MAT1-2 sequences of both species contain three exons. The predicted length of the genes, as well as exon and intron positions, is illustrated in Figure 2. Although the number of nucleotide and amino acid residues was the same for the MAT1-2 of the two Dothistroma spp., an identity of 94.4 and $92.7 \%$ was found between the 1,012-nucleotide and the 302-aa residues, respectively. All the introns found for both species contained a perfect lariat sequence. The number of predicted introns (two) of the Dothistroma spp. studied correlates with the number predicted for Cercospora spp. (25), but the specific locations of these introns within the gene differed. Only one predicted intron was found in the HMG domain of species of Cercospora (25), M. graminicola (51), and S. passerinii (23), whereas two predicted introns were found in the same region of the Dothistroma spp. studied.

Screening with $D$. pini and $D$. septosporum mating-typespecific primers. In the $D$. pini MAT1 isolates, DpiniMat1f2 and DotMat1r amplified an 820-bp fragment and, in the D. pini MAT2 isolates, DpiniMat2f and DotMat2r amplified a 480-bp fragment (Fig. 3). Each isolate tested showed either the 820- or 480-bp fragment of the MAT1-1-1 or MAT1-2 genes, respectively. None of the isolates contained both fragments. The $D$. pini mating-typespecific primers did not amplify the MAT1-1-1 and MAT1-2 fragments in any of the D. septosporum isolates (Fig. 3). The majority of the $D$. pini isolates were from areas in the United States where both mating types are known to exist. Eight isolates of each mating type were found for these $D$. pini isolates, whereas only MAT1 isolates were found for the $D$. pini collection from the Ukraine (Table 1). In the D. septosporum MAT1 isolates, DseptoMat1f2 and DotMat1r amplified an 820-bp fragment; in the D. septosporum MAT2 isolates, DseptoMat2f and DotMat2r amplified a 480-bp fragment (Fig. 3). Each isolate tested showed either the 820- or 480-bp fragment of the MAT1-1-1 or MAT1-2 genes, respectively. None of the isolates amplified both fragments.

The D. septosporum mating-type-specific primers did not amplify the MAT1-1-1 and MAT1-2 fragments of the D. pini isolates (Fig. 3). In all, 20 D. pini and 210 D. septosporum isolates (Table 1) were screened with the two mating-type-specific primer sets to determine the mating type and to confirm the identity of each isolate. All D. septosporum isolates obtained from Chile, Australia, and New Zealand contained only the MAT1-2. In contrast, isolates representing both mating types were present in the Austria, Canada, Poland, South Africa, and United Kingdom collections. Only one isolate was available each from Germany, Brazil, France, Guatemala, Slovakia, and the United States. All of these isolates contained the MAT1-2 gene, except for the isolate from Slovakia that contained MAT1-1-1.

Phylogenetic analyses. The alignment of partial MAT1-1-1 nucleotide sequences ( $\alpha$ domain) contained 21 strains, including $M$. grisea as the outgroup, and had a total length of 174 characters. Of the 174 characters, 23 were constant, 15 were variable and uninformative, and 136 were parsimony informative. The alignment of partial MAT1-2 nucleotide sequences (HMG domain) contained 21 strains, including $M$. grisea as outgroup, and had a total length of 253 characters. Of the 249 characters, 37 were constant, 13 were variable and uninformative, and 199 were parsimony informative. Two equally parsimonious trees were obtained from each of the MAT1-1 alignments (Fig. 4A; tree length of 638 steps; $\mathrm{CI}=0.498, \mathrm{RI}=0.649, \mathrm{RC}=0.324)$ and from the MAT1-2 alignment (Fig. 4B; tree length of 886 steps; $\mathrm{CI}=0.512, \mathrm{RI}=0.659, \mathrm{RC}=0.338)$.

The topology of the phylogenetic trees using the $\alpha$ domain (Fig. 4A) and HMG domain (Fig. 4B) sequences were similar.

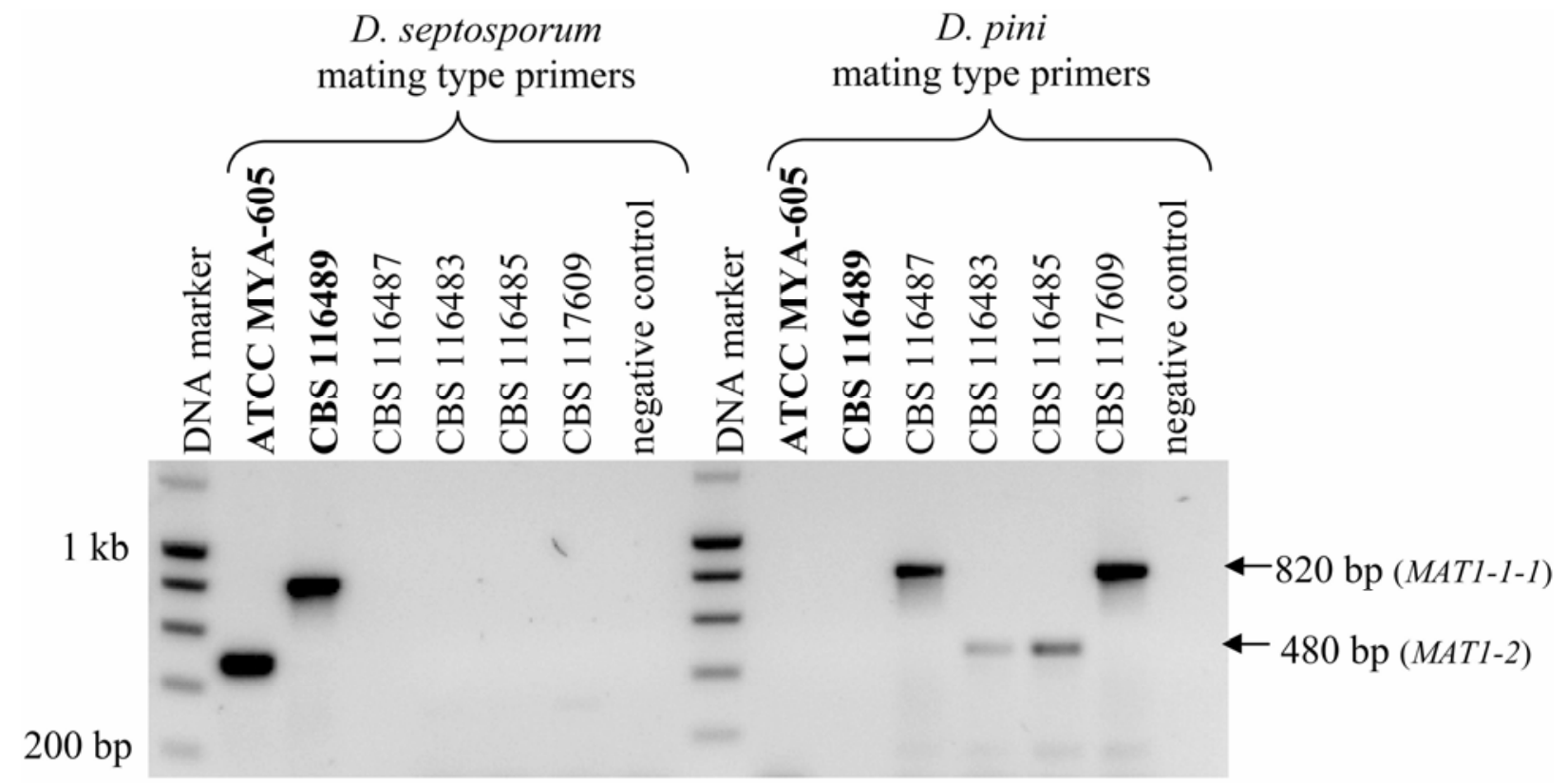

Fig. 3. Dothistroma septosporum (bold face) and D. pini isolates screened using the Dsepto/Dpini/DotMat1 primer set (820-bp fragment) and the same Dothistroma isolates screened with the Dsepto/Dpini/DotMat2 primer set (480-bp fragment). 
The Capnodiales, Hypocreales, and Pleosporales clades showed high bootstrap support (92 to 97\%) in both trees. The phylogenetic analysis using the DNA sequences in the HMG-box and $\alpha$ domain showed that $D$. pini and $D$. septosporum, respectively, are phylogenetically closely related to Cercospora spp., M. graminicola, and S. passerinii as illustrated by the $92 \%$ (MAT1-1-1) and 97\% (MAT1-2) bootstrap support values.

\section{DISCUSSION}

This study represents the first attempt to ascertain which mating types are present in the different countries where diseases caused by $D$. septosporum and $D$. pini occur. In this regard, emphasis is on D. septosporum, because it has been introduced into numerous countries, where it has caused very damaging disease problems. Thus, the degenerate primer sets MgMfSpMAT1-1 and MgMfSpMAT1-2 (25) were used successfully to amplify portions of the mating type genes of D. septosporum and D. pini. This made it possible to characterize the full-length MAT1-1-1 or MAT1-2 genes of both species.

The MAT1-1-1 and MAT1-2 genes characterized for D. septosporum and $D$. pini in this study contained areas that correspond to a putative $\alpha$ domain and an HMG domain also described for the MAT1-1-1 and MAT1-2 of other ascomycetes. The two putative introns in the $\alpha$ domains of the Dothistroma MAT1-1-1 also have been found in corresponding areas in M. graminicola (50), $S$. passerinii (23), and several Cercospora spp. (25). However, the third predicted intron in the downstream area flanking the $\alpha$ domain of the MAT1-1-1 of both Dothistroma spp. is present only in the Cercospora sp., and not in M. graminicola or $S$. passerinii. The number of introns found in the HMG domain of the MAT1-2 in both Dothistroma spp. differed from that of closely related species. The first predicted intron also is present in $M$. graminicola (50), S. passerinii (23), and Cercospora spp. (25). In contrast, the second predicted intron is present only in the MAT1-2 of the Dothistroma spp., and not in any other members of the Mycosphaerellaceae thus far studied. These data indicate that clear differences can be found even within the conserved regions of the corresponding genes in different Mycosphaerella spp.

The predicted length of the encoded proteins among different MAT1-1-1 and MAT1-2 genes of ascomycetes varies greatly $(23,25,40)$. In most species, the MAT1 protein is much larger than the MAT2. Results of this study have shown that this also is the case for the Dothistroma spp., where 387 aa were found for MAT1 and 302 aa for MAT2. Expression studies have not been done on the mating type genes of any of the above-mentioned members of the Mycosphaerellaceae. Additional studies at the mRNA and protein levels would be necessary to confirm the exact length of the coding regions and the intron and exon boundaries for the mating type genes of the Dothistroma spp.

Results of this study showed substantial differences between the nucleotide as well as amino acid sequences of the corresponding mating type genes and proteins of D. septosporum and $D$. pini. Using nucleotide sequences for phylogenetic inference in these fungi is consistent with previous studies where conserved domains within the mating type genes have been used to study the phylogenetic relationships among different fungal species and families $(12,25,34,35,52)$. Differences in mating type sequences
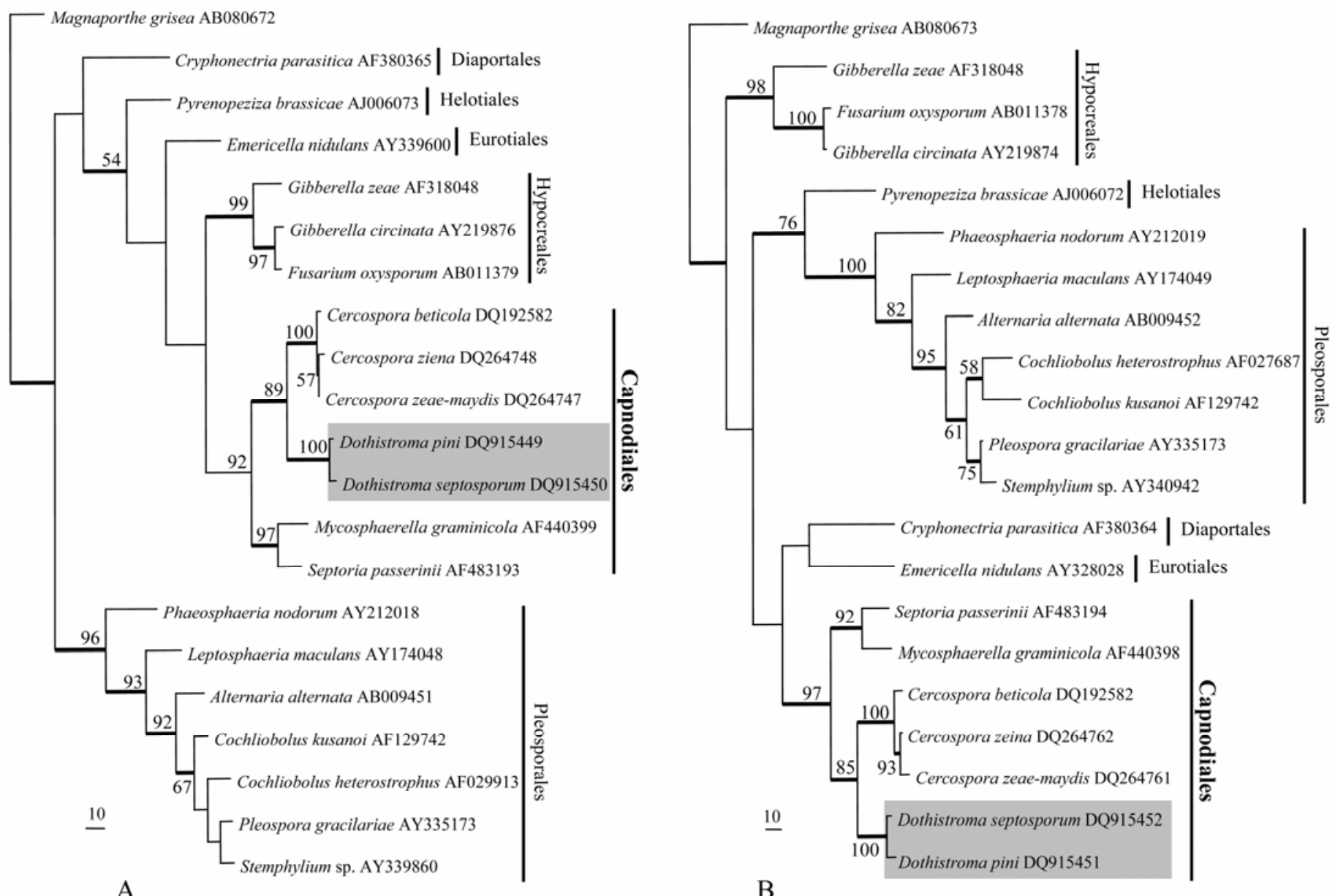

Fig. 4. One of two equally parsimonious trees obtained from each of the A, MAT1-1-1 sequence alignment rooted to Magnaporthe grisea (AB080672) and B, MAT1-2 sequence alignment rooted to $M$. grisea (AB080673). In both trees, bootstrap support values from 1,000 replicates are shown at the nodes, whereas thickened lines indicate strict consensus branches. 
for $D$. septosporum and $D$. pini show that these species are distinct genetic entities and provides strong support for the results of Barnes et al. (2), who provided the first DNA-based evidence that the species are distinct.

Based on morphological characteristics, Barr (3) attempted to reclassify Mycosphaerella pini in a new genus outside of $M y$ cosphaerella. However, molecular phylogenetic analyses have shown that Mycosphaerella is the most appropriate designation for this fungus classification (2,22). Phylogenetic analyses, based on the sequences of the HMG and $\alpha$ domains, also confirm that Dothistroma spp. are members of the Mycosphaerellaceae. All remaining species also grouped within their corresponding families; however, the relationship between different families is unresolved.

The mating-type-specific primer sets developed in this study, DpiniMat1 and DpiniMat2 as well as DseptoMat1 and DseptoMat2, can be used effectively in multiplex PCR assays to amplify areas within the mating type genes for $D$. pini and $D$. septosporum populations, respectively. These primers also can be used to distinguish between the two Dothistroma spp., making them useful tools for rapid and accurate diagnoses of two important pathogens that are morphologically similar. Prior to this study, the only diagnostic tool available to distinguish between $D$. pini and D. septosporum, was to amplify the ITS of the ribosomal DNA region with universal primers and then to digest the amplicon with the restriction endonuclease $A l u I$ (2). Although the latter technique is useful, the ITS amplicon of $D$. pini is digested into two fragments whereas that of D. septosporum is not. Therefore, to prevent a false positive result for D. septosporum, a prior confirmation that the fungus is a Dothistroma $\mathrm{sp}$. is required. The mating-type-specific primer sets emerging from this study are species specific and do not require a prior view on the identity of unknown isolates. They are, therefore, multifunctional and can be used for the rapid identification of the species as well as its mating type.

Although results of this study have shown that $D$. pini is probably heterothallic with a single isolate containing only one of the two mating type genes, no teleomorph has yet been linked to this species. Where both mating types were observed for the isolates from the United States, the sexual state most likely is present, but has not been observed. In contrast, the $M$. pini teleomorph of D. septosporum previously has been observed in some parts of the United States $(9,38,39)$ where $D$. pini is predominantly found. Given that the anamorphs of these fungi are morphologically similar and have been confused in the past, it is possible that teleomorph structures reported for D. septosporum could have been linked to $D$. pini and not to D. septosporum.

Although a small number of isolates were screened for most countries, this study shows that D. septosporum probably are heterothallic and that one mating type (MAT2) seems to be more prevalent in several of the collections studied (e.g., New Zealand). Although sexual reproduction has been confirmed in D. septosporum, asexual reproduction happens more frequently, and the absence or rarity of the opposite mating type (MAT1) in most of the collections can explain the common occurrence of the asexual stage. Therefore, it also is possible that the teleomorph is not as rare as first believed. We found that both mating types exist within D. septosporum populations from Europe (Poland and Austria) and Canada, where the sexual stage (M. pini) has been reported in the past $(7,15,17,28,29)$. However, the teleomorph has never been found in countries in the Southern Hemisphere such as Chile, Australia, and New Zealand, where these pathogens have long been a major problem $(14,31)$. These are also the countries for which only one mating type (MAT2) has been observed, and this might explain the absence or rarity of the sexual stage.

Discovery in this study of only a single mating type of D. septosporum in New Zealand, Australian, and Chilean collections can be explained by the fact that the fungus is an introduced pathogen in those countries. For New Zealand, Hirst et al. (26) also found that no genetic variation exist among isolates of a D. septosporum population, which is strongly supported by the results of the present study. Dothistroma needle blight was introduced in Australia in the 1970s and it was suggested that this occurred by natural means, with conidia being blown across the Tasman Sea from New Zealand. This view was supported by the fact that the strict quarantine regulations in Australia would have made it unlikely that infected plant material entered the country $(13,31,33)$. The presence of only one mating type shown in this study and the fact that no genetic diversity has been found yet for the pathogen in New Zealand (26) supports the view that only one genotype was introduced into or became established in Australia and New Zealand. Asexual reproduction evidently has perpetuated the spread of the fungus subsequently. We suspect that the same situation will have been true for Chile.

An intriguing result of this study has been the discovery that both mating types of $D$. septosporum exist in the South African and United Kingdom collections. This is especially interesting because the pathogen is non-native in these countries and it might have been expected that the situation would have been similar to that in other countries such as New Zealand, where the pathogen also is an alien invasive. In addition, the teleomorph of D. septosporum has never been observed in South Africa (M. J. Wingfield, unpublished data) and the United Kingdom (A. V. Brown, unpublished data), despite concerted efforts to detect it.

It is important to recognize that the presence of both mating types of D. septosporum in these two countries could indicate the presence of clandestine sex in the fungus. This would indicate the potential for the pathogen to evolve more effectively in these countries than would be true elsewhere in the world, where only a single mating type exists. Such change in the fungus could complicate efforts to develop trees resistant to Dothistroma needle blight infection in South Africa and the United Kingdom. In this regard, it has been shown previously that the introduction of the second mating type of a pathogen can cause rapid increase in virulence, gene transfer, and genetic variation, such as in Phytophthora infestans $(16,30,42,45)$ and Ophiostoma novo-ulmi (36). This implies that the accidental introduction of the opposite mating type of D. septosporum into countries such as New Zealand, Australia, and Chile could seriously exacerbate red band needle disease in those countries. Thus, every effort must be made to ensure that new mating types of $D$. septosporum do not enter these countries.

There has been a dramatic increase in the impact of Dothistroma needle blight caused by D. septosporum in western Canada, the United States, and the United Kingdom in recent years $(5,6,53)$. Possible reasons for this change in the disease situation in these countries are an abundance of host material or a directional climate change, as suggested by Woods et al. (54). The discovery that both mating types exist in these countries is another factor that can contribute to the change in the disease situation. The presence of both mating types increases the possibility for sexual reproduction. This, in turn, can lead to the exchange of genetic material between different strains, resulting in a possible increase in the viability of this species. Therefore, further investigation is necessary to determine whether the presence of both mating types, which could increase genetic diversity, a dramatic climate change, or possibly a combination of both these factors might account for the drastic increase in the severity of this disease.

Because only one mating type of D. septosporum appears to be present in most countries of the Southern Hemisphere, it is important to restrict the MAT1 isolates to their present locations. This can be achieved through refining quarantine regulations based on the knowledge that only one mating type of the pathogen is present in the country. The mating-type-specific PCR developed during this study could be implemented easily as a control method to 
test for the presence of the mating types for Dothistroma spp. in pine plantations. One of the weaknesses of quarantine regulations internationally is that they typically rely on lists of names of pathogens rather than on knowledge of their biology and population genetics. Results of this study have provided valuable new insights into the distribution of mating types of D. septosporum and $D$. pini that should enhance the quality of quarantine regulations in the future.

\section{ACKNOWLEDGMENTS}

We thank the CBS-Odo van Vloten Stichting and the Royal Netherlands Academy of Arts and Sciences for financial support to $\mathrm{M}$. Groenewald; G. C. Adams (United States), T. Kirisits (Austria), T. Kowalski (Poland), R. Ahumada (Chile), and A. Carnegie (Australia) for providing specimens of D. pini and D. septosporum; and M. Guo for technical assistance.

\section{LITERATURE CITED}

1. Altschul, S. F., Madden, T. L., Schaffer, A. A., Zhang, J., Zhang, Z., Miller, W., and Lipman, D. J. 1997. Gapped BLAST and PSI-BLAST: A new generation of protein database search programs. Nucleic Acids Res. 25:3389-3402.

2. Barnes, I., Crous, P. W., Wingfield, B. D., and Wingfield, M. J. 2004. Multigene phylogenies reveal that red band needle blight of Pinus is caused by two distinct species of Dothistroma, D. septosporum and D. pini. Stud. Mycol. 50:551-565.

3. Barr, M. E. 1996. Planistromellaceae, a new family in the Dothideales. Mycotaxon 60:433-442.

4. Bobrowicz, P., Pawlak, R., Correa, A., Bel-Pedersen, D., and Ebbole, D. J. 2002. The Neurospora crassa pheromone precursor genes are regulated by the mating type locus and the circadian clock. Mol. Microbiol. 45:795804.

5. Bradshaw, R. E. 2004. Dothistroma (red-band) needle blight of pines and the dothistromin toxin: a review. For. Pathol. 34:163-185.

6. Brown, A. V., Rose, D, R., and Webber, J. F. 2003. Red Band Needle Blight of Pine. Forest Research Information Note 49. Forestry Commission, Edinburgh.

7. Butin, H., and Richter, J. 1983. Dothistroma needle blight: a new pine disease in the Federal Republic of Germany. Nachrichtenbl. Deut. Pflanzenschutzel. 35:129-131.

8. Carson, S. D., Dick, A. M. P., and West, G. G. 1991. Benefits of the Dothistroma-resistant breed of radiata pine. Pages 251-262 in: New Directions in Forestry Costs and Benefits of Change. J. C. Allen and A. G. D. Whyte, eds. Aust. \& N. Z. Inst. Forestry, Christchurch, New Zealand.

9. Cobb, F. W., and Miller, D. R. 1968. Hosts and geographic distribution of Scirrhia pini-the cause of red band needle blight in California. J. For. 66:930-933.

10. Cobb, F., Uhrenholdt, B., and Drohn, R. 1969. Epidemiology of Dothistroma pini needle blight on Pinus radiata. Phytopathology 59:10211022.

11. Coops, N., Stanford, M., Old, K., Dudzinski, M., Culvenor, D., and Stone, C. 2003. Assessment of Dothistroma needle blight of Pinus radiata using airborne hyperspectral imagery. Phytopathology 93:1524-1532.

12. Du, M., Schardl, C. L., Nuckles, E. M., and Vaillancourt, L. J. 2005. Using mating-type gene sequences for improved phylogenetic resolution of Colletotrichum species complexes. Mycologia 97:641-658.

13. Edwards, D. W., and Walker, J. 1978. Dothistroma needle blight in Australia. Aust. For. Res. 8:125-137.

14. Evans, H. C. 1984. The genus Mycosphaerella and its anamorphs Cercoseptoria, Dothistroma and Lecanosticta on pines. Mycol. Pap. 153:1-102.

15. Fonseca, N. 1998. Mycosphaerella pini (Scirrhia pini), the perfect state of Dothistroma septospora: first observation in Portugal. Pages 69-74 in: Foliage, Shoot and Stem Diseases of Trees. G. Laflamme, J. A. Bèrubé, and R. C. Hamelin, eds. Can. For. Serv., Quebec City, Canada.

16. Fry, W. E., and Goodwin, S. B. 1997. Re-emergence of potato and tomato late blight in the United States. Plant Dis. 81:1349-1357.

17. Funk, A., and Parker, A. K. 1966. Scirrhia pini n. sp., the perfect state of Dothistroma pini Hulbary. Can. J. Bot. 44:1171-1176.

18. Gasteiger, E., Gattiker, A., Hoogland, C., Ivanyi, I., Appel, R. D., and Bairoch, A. 2003. ExPASy: the proteomics server for in-depth protein knowledge and analysis. Nucleic Acids Res. 31:3784-3788.

19. Gibson, I. A. S. 1972. Dothistroma blight of Pinus radiata. Annu. Rev. Phytopathol. 10:51-72.
20. Gibson, I. A. S. 1974. Impact and control of Dothistroma blight of pines. Eur. J. For. Pathol. 4:89-100.

21. Gilmour, J. W. 1967: Distribution and significance of the needle blight of pines caused by Dothistroma pini in New Zealand. Plant Dis. Rep. 51:727-730.

22. Goodwin, S. B., Dunkle, L. D., and Zismann, V. L. 2001. Phylogenetic analysis of Cercospora and Mycosphaerella based on the internal transcribed spacer region of ribosomal DNA. Phytopathology 91:648-658.

23. Goodwin, S. B., Waalwijk, C., Kema, G. H. J., Cavaletto, J. R., and Zhang, G. 2003. Cloning and analysis of the mating-type idiomorphs from the barley pathogen Septoria passerinii. Mol. Gen. Genomics 269:112 .

24. Groenewald, M., Groenewald, J. Z., and Crous, P. W. 2005. Distinct species exist within the Cercospora apii morphotype. Phytopathology 95:951-959.

25. Groenewald, M., Groenewald, J. Z., Harrington, T. C., Abeln, E. C. A., and Crous, P. W. 2006. Mating type gene analysis in apparently asexual Cercospora species is suggestive of cryptic sex. Fungal Genet. Biol. 43:813-825.

26. Hirst, P., Richardson, T. E., Carson, S. D., and Bradshaw, R. E. 1999. Dothistroma pini genetic diversity is low in New Zealand. New Zeal. J. For. Sci. 29:459-472.

27. Ivory, M. H. 1967. A new variety of Dothistroma pini in Kenya. Trans. Br. Mycol. Soc. 50:289-297.

28. Karadzic, D. 1989. Scirrhia pini Funk et Parker. Life cycle of the fungus in plantations of Pinus nigra. Arn. in Serbia. Eur. J. For. Pathol. 19:231236.

29. Kowalski, T., and Jankowiak, R. 1998. First record of Dothistroma septospora (Dorog.) Morelet in Poland: a contribution to the symptomology and epidemiology. Phytopathol. Pol. 16:15-29.

30. Lee, Y. S., and Kim K. J. 2002. Genetic DNA marker for A2 mating type in Phytophthora infestans. J. Microbiol. 40:254-259.

31. Marks, G. C., Smith, I. W., and Cook, I. O. 1989. Spread of Dothistroma septospora in plantations of Pinus radiata in Victoria between 1979 and 1988. Aust. For. 52:10-19.

32. Metzenberg, R. L., and Glass, N. L. 1990. Mating type and mating strategies in Neurospora. BioEssays 12:53-59.

33. Mireku, E., and Simpson, J. A. 2002. Fungal and nematode threats to Australian forests and amenity trees from importation of wood and wood products. Can. J. Plant Pathol. 24:117-124.

34. O’Donnell, K., Ward, T. J., Geiser, D. M., Kistler, H. C., and Aoki, T. 2004. Genealogical concordance between the mating type locus and seven other nuclear genes supports formal recognition of nine phylogenetically distinct species within the Fusarium graminearum clade. Fungal Genet. Biol. 41:600-623.

35. Paoletti, M., Buck, K. W., and Brasier, C. M. 2005. Cloning and sequence analysis of the MAT-B (MAT-2) genes from the tree Dutch elm disease pathogens, Ophiostoma ulmi, O. novo-ulmi, and O. himal-ulmi. Mycol. Res. 109:983-991.

36. Paoletti, M., Buck, K. W., and Brasier, C. M. 2006. Selective acquisition of novel mating type and vegetative incompatibility genes via interspecies gene transfer in the globally invading eukaryote Ophiostoma novo-ulmi. Mol. Ecol. 15:249-262.

37. Pearson, W. R., Wood, T., Zhang, Z., and Miller, W. 1997. Comparison of DNA sequences with protein sequences. Genomics 46:24-36.

38. Peterson, G. W. 1982. Dothistroma needle blight of pines. In: Forest Insect and Disease Leaflet 143. U. S. Dep. Agric. For. Serv., Washington, DC.

39. Peterson, G. W., and Harvey, G. M. 1976. Dispersal of Scirrhia (Dothistroma) pini conidia and disease development in a shore pine plantation in western Oregon. Plant Dis. Rep. 60:761-764.

40. Pöggeler, S. 2001. Mating-type genes for classical strain improvements of ascomycestes. Appl. Microbiol. Biotechnol. 56:589-601.

41. Ray, J. W., and Vanner, A. L. 1988. Improvements in the Technology of Dothistroma Control. What's New in Forest Research No. 169. New Zealand Research Institute, Rotorua.

42. Ristaino, J. B. 2002. Tracking historic migrations of the Irish potato famine pathogen, Phytophthora infestans. Microbes Infect. 4:1369-1377.

43. Singh, G., and Ashby, A. M. 1998. Cloning of the mating-type loci from Pyrenopeziza brassicae reveals the presence of a novel mating type gene within a discomycete MAT1-2 locus encoding a putative metallothioninlike protein. Mol. Microbiol. 30:799-806.

44. Singh, G., and Ashby, A. M. 1999. Erratum to Singh and Ashby 1998. Cloning of the mating-type loci from Pyrenopeziza brassicae reveals the presence of a novel mating type gene within a discomycete MAT1-2 locus encoding a putative metallothionin-like protein. Mol. Microbiol. 32:1115.

45. Smart, C. D., and Fry, W. E. 2001. Invasions by the late blight pathogen: Renewed sex and enhanced fitness. Biol. Invas. 3:235-243.

46. Stone, C., Chisholm, L. A., and McDonald, S. 2003. Spectral reflectance characteristics of Pinus radiata needles affected by Dothistroma needle 
blight. Can. J. Bot. 81:560-569.

47. Turgeon, B. G. 1998. Application of mating type gene technology to problems in fungal biology. Annu. Rev. Phytopathol. 36:115-137.

48. Turgeon, B. G., Bohlmann, H., Ciuffetti, L. M., Christiansen, S. K., Yang, G., Schafer, W., and Yoder, O. C. 1993. Cloning and analysis of the mating type genes from Cochliobolus heterostrophus. Mol. Gen. Genet. 238:270-284.

49. Turgeon, B. G., and Yoder, O. C. 2000. Proposed nomenclature for mating type genes of filamentous ascomycetes. Fungal Genet. Biol. 31:1-5.

50. Waalwijk, C., Mendes, O., Verstappen, E. C., de Waard, M. A. D., and Kema, G. H. J. 2002. Isolation and characterization of the mating-type idiomorphs from the wheat Septoria leaf blotch fungus Mycosphaerella graminicola. Fungal Genet. Biol. 35:277-286.

51. Wingfield, M. J, Slippers, B., Roux, J., and Wingfield, B. D. 2001. Worldwide movement of exotic forest fungi, especially in the tropics and the Southern Hemisphere. BioScience 51:134-140.
52. Witthuhn, R. C., Harrington, T. C., Steimel, J. P., Wingfield, B. D., and Wingfield, M. J. 2000. Comparison of isozymes, rDNA spacer regions and MAT-2 DNA sequences as phylogenetic characters in the analysis of the Ceratocystis coerulescens complex. Mycologia 92:447-452.

53. Woods, A. J. 2003. Species diversity and forest health in northwest British Columbia. For. Chronobiol. 79:892-897.

54. Woods, A., Coates, K. D., and Hamann, A. 2005. Is an unprecedented Dothistroma needle blight epidemic related to climate change? BioScience 55:761-769.

55. Yun, S. H., Arie, T., Kaneko, I., Yoder, O. C., and Turgeon, B. G. 2000. Molecular organization of mating type loci in heterothallic, homothallic, and asexual Gibberella/Fusarium species. Fungal Genet. Biol. 31:7-20.

56. Zhan, J., Kema, G. H. J., Waalwijk, C., and McDonald, B. A. 2002. Distribution of mating type alleles in the wheat pathogen Mycosphaerella graminicola over spatial scales from lesions to continents. Fungal Genet. Biol. 36:128-136. 